Proc. Estonian Acad. Sci. Eng., 2005, 11, 2, 154-160

\title{
Models of fuel spray penetration
}

\author{
Sergei Sazhin ${ }^{\mathrm{a}}$, Cyril Crua ${ }^{\mathrm{a}}$, Jin-Sik Hwang ${ }^{\mathrm{b}}$, Soo-Young $\mathrm{No}^{\mathrm{b}}$ \\ and Morgan Heikal ${ }^{\mathrm{a}}$ \\ a School of Engineering, Faculty of Science and Engineering, University of Brighton, \\ Cockcroft Building, Brighton BN2 4GJ, United Kingdom; s.sazhin@bton.ac.uk \\ b Department of Agricultural Machinery Engineering, Chungbuk National University, \\ Cheongju, 361-763, Korea
}

Received 16 January 2004

\begin{abstract}
A brief review of models of diesel fuel spray penetration, developed at the University of Brighton, are presented. These refer to the initial stage of spray penetration and the twophase flow stage, when the relative velocity between droplets and gas can be ignored. The predictions of the two-phase models of spray penetration are compared with the results of experimental studies. A rapid compression diesel spray rig, based at Brighton University, and a high-pressure dimethyl ether spray chamber, based at Chungbuk National University, have been used. In both cases the experimental results are shown to be in agreement with the prediction of theoretical models.
\end{abstract}

Key words: diesel fuel spray, dimethyl ether spray, two-phase flow, spray penetration.

\section{INTRODUCTION}

A rigorous theory of spray penetration would be very complex as it would need to involve modelling of the formation of ligaments and their breakup, droplet breakup and evaporation, the entrainment of air and the effects of turbulence $\left[{ }^{1}\right]$. A self-consistent model of all these processes is still a major challenge. However, this modelling is not always essential for understanding the process and engineering applications. On many occasions it is far more important to establish a "hierarchy" of the importance of various processes and to develop simplified models suitable for practical applications.

Some results in this direction were reported in $\left[{ }^{2}\right]$, where simple analytical models, describing the initial stage of spray penetration and droplet breakup, were 
derived. The reduction of the droplet size due to the breakup was considered, but an unrealistic assumption that droplet velocity remains constant, was used. The effects of reduction of the droplet size during the penetration process due to effects of evaporation and breakup were ignored. These will be taken into account in the present analysis.

This model was further developed in $\left[{ }^{3}\right]$, where effects of droplet evaporation, breakup and air entrainment on diesel fuel spray penetration were studied theoretically at the initial stage of spray penetration, when the influence of air entrainment is small (up to $0.1-0.2 \mathrm{~ms}$ after the start of injection). Theoretical plots of spray penetration versus time were compared with experimental results, obtained using an optical single cylinder rapid compression test rig based on a Ricardo Proteus engine. Three models of spray penetration were compared. In the first, neither breakup nor air entrainment were taken into account. The breakup processes (bag and stripping) were taken into account in the second model, while in the third model both bag breakup and air entrainment processes were considered. It was found that the agreement between the predictions of the third model with experimental measurements is better than that for the first two models.

It was shown in $\left[{ }^{2}\right]$ that for realistic diesel spray parameters the droplet breakup takes place almost immediately after the droplets leave the nozzle. This leads to a considerable shortening of the initial stage and a rapid conversion of the flow to the two-phase stage. This allows the analysis to be restricted to the two-phase flow approximation for this type of spray, when the expressions for spray penetration are derived, based on the equations of conservation of mass and momentum. The expressions for spray penetration derived in $\left[{ }^{2}\right]$ gave more accurate predictions compared with those suggested earlier. This conclusion, however, was reached based on just two cases taken from the literature, and cannot be considered to be reliable. Further generalization of this model, taking into account the effect of turbulence, was reported in $\left[{ }^{4}\right]$.

The focus of this paper will be on the two-phase models of spray penetration. These models will be compared with the observed spray penetrations, using rather different experimental set-ups at the University of Brighton $\left[{ }^{5-7}\right]$ and Chungbuk National University of Korea $\left.{ }^{8,9}\right]$.

The two-phase models for spray penetration, suggested in $\left[{ }^{2}\right]$, are briefly reviewed in Section 2. The experimental set-ups used are described in Section 3. Comparison between experimental and theoretical results is presented in Section 4. The main results of the paper are summarized in Section 5.

\section{TWO-PHASE FLOW}

The analysis of the influence of the air jet on spray dynamics in the area beyond the vicinity of the nozzle appears to be a rather difficult task. At the same time, as the distance from the nozzle increases, the velocities of droplets approach the velocity of the entrained air. As a result, the dynamics of both droplets and 
entrained air can be described in terms of a two-phase flow with a zero relative velocity between air and droplets. The basic properties of this flow can be derived from the equations of conservation of mass and momentum. Omitting the details of the analysis, the final equation can be presented as $\left[^{2}\right]$ :

$$
s=\frac{\sqrt{v_{\text {in }} D_{0} t}}{\left(1-\alpha_{d}\right)^{1 / 4}{\tilde{\rho_{a}}}^{1 / 4} \sqrt{\tan \theta}}\left(1-\frac{\sqrt{D_{0}}}{4 \sqrt{v_{\text {in }}}\left(1-\alpha_{d}\right)^{1 / 4}{\tilde{\rho_{a}}}^{1 / 4} \sqrt{\tan \theta} \sqrt{t}}\right),
$$

where $D_{0}$ is the nozzle orifice diameter $(\mathrm{m}), s$ is the liquid spray tip penetration $(\mathrm{m}), t$ is the time after start of injection (s), $v_{\text {in }}$ is the initial velocity of fuel spray $(\mathrm{m} / \mathrm{s}), \alpha_{d}$ is the volume fraction of droplets in the spray (dimensionless), $\theta$ is half of the liquid spray cone angle (radians) and $\tilde{\rho_{a}}$ is the ratio of air density to liquid fuel density (dimensionless).

Equation (1) can be further simplified if the second term on the right hand side is ignored, thus giving

$$
s=\frac{\sqrt{v_{\text {in }} D_{0} t}}{\left(1-\alpha_{d}\right)^{1 / 4}{\tilde{\rho_{a}}}^{1 / 4} \sqrt{\tan \theta}} .
$$

Equation (2) for spray penetration is identical to the one suggested by a number of authors. From this point of view, Eq. (1) can be considered as a generalization of previously discussed formulae.

\section{EXPERIMENTAL SET-UPS}

A high-pressure diesel spray rig was installed in 1999 at the University of Brighton. This rapid compression machine is based around a Ricardo Proteus single cylinder engine converted to liner ported, 2 stroke cycle operation $\left[{ }^{5-7}\right]$. This facility allows the testing of a wide range of injectors at different fuelling rates and pressures. The spray is injected into the optical chamber, where incylinder pressures and temperatures up to $12 \mathrm{MPa}$ and $750 \mathrm{~K}$, respectively, can be achieved, by preconditioning the boost air supply. The optical chamber gives good visual access to the fuel spray. The window dimensions are $55 \mathrm{~mm}$ in height and $25 \mathrm{~mm}$ in width. A second generation Bosch common rail system $\left[{ }^{10}\right]$ was used for this work, with a maximum rail pressure capability of $160 \mathrm{MPa}$. The fuel pump was powered by an electric motor running at $1400 \mathrm{rpm}$, ensuring a stable rail pressure with minimal fluctuation. The rail and delivery pipe were both instrumented with a 4067 Kistler pressure transducer. The pipe from the rail to the injector was kept short, representative of a real automotive system. The fuel used was a low sulphur reference fuel, representative of an automotive diesel fuel with a density of $837 \mathrm{~kg} \mathrm{~m}^{-3}$ and sulphur content of $0.02 \%$ by mass. A custom controller was developed $\left[{ }^{5}\right]$. This enabled independent control of injection timing, injection duration and rail pressure. The injector was fitted with a single-hole 
VCO type nozzle, with a $0.2 \mathrm{~mm}$ hole diameter. The single-hole nozzle design had an equivalent cone angle of $130^{\circ}$. The injector hole was manufactured using a conventional spark erosion technique and then micro-honed to produce an entry radius and surface finish, representative of a production nozzle. The needle was of the single-guided type and was instrumented with a Hall-effect-type needle lift sensor. Fuel rail pressure and needle lift were monitored on a digital storage oscilloscope. The processing of the videos was performed by purpose-developed software that measures the spray penetration length and spray cone angle at each video frame after suitable pixel thresholding. An example of a raw image and its thresholded equivalent is shown in Fig. 1.

The experimental set-up, installed at Chungbuk National University, consists of a high-pressure chamber, common rail system injector, fuel pump, air compressor, pressure regulator and particle motion analysis system (PMAS) $\left[{ }^{9}\right]$. The fuel supply system in this study was organized by considering the high vapour pressure of dimethyl ether (DME). In order to avoid vaporization in the fuel line, it was pressurized from the fuel tank to the fuel pump using nitrogen at 1.6 MPa. To avoid the leakage of DME in the fuel line, a solenoid valve and sensor were used. The fuel was supplied to the injector by a fuel pump, operated with an air compressor. The injection pressure was kept constant by a regulator. The DME was pressurized at $35 \mathrm{MPa}$ and then injected into the high-pressure chamber that was filled with nitrogen at ambient pressure of $0.6,1.0$ and $1.5 \mathrm{MPa}$. The nozzle hole diameters tested were of $0.2,0.3$ and $0.4 \mathrm{~mm}$. The injection period and injection timing were controlled by changing the pulse signal of the PMAS. The spray tip penetration was measured by using the shadowgraph technique. It consists of a spark light
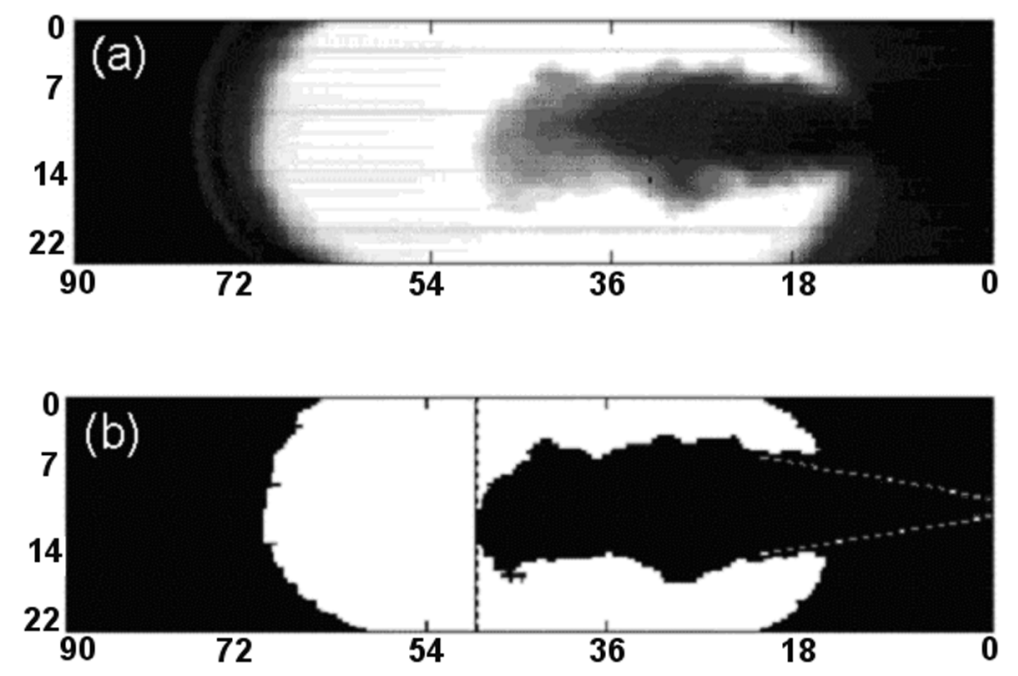

Fig. 1. (a) Raw digital spray image; (b) thresholded image showing measured penetration length; scales are given in mm-s. 
source with a duration of about $50 \mathrm{~ns}$, a field lens, a CCD camera and a personal computer with an image acquisition board. The error of spray tip penetrations, measured using the PMAS and the high-pressure chamber, was found to vary from 10 to $15 \%$.

\section{RESULTS}

Figure 2 shows the comparison between calculated and measured spray tip penetration for both experimental test beds. It is clear from this figure that the spray tip penetrations predicted by Eqs. (1) and (2) are very close and in good agreement with the measured penetrations, even though the equipment used and the range of ambient densities tested varied significantly between the two studies. It is also apparent that the prediction of the model, developed for diesel fuel spray tip penetration, can be applied to DME fuel sprays. It can be observed from Fig. 2 that both Eqs. (1) and (2) accurately predicted the spray tip penetrations for both experimental rigs, even though significant differences in fuel type, injection pressure, spray angle and ambient gas density existed. Sometimes (e.g. the case
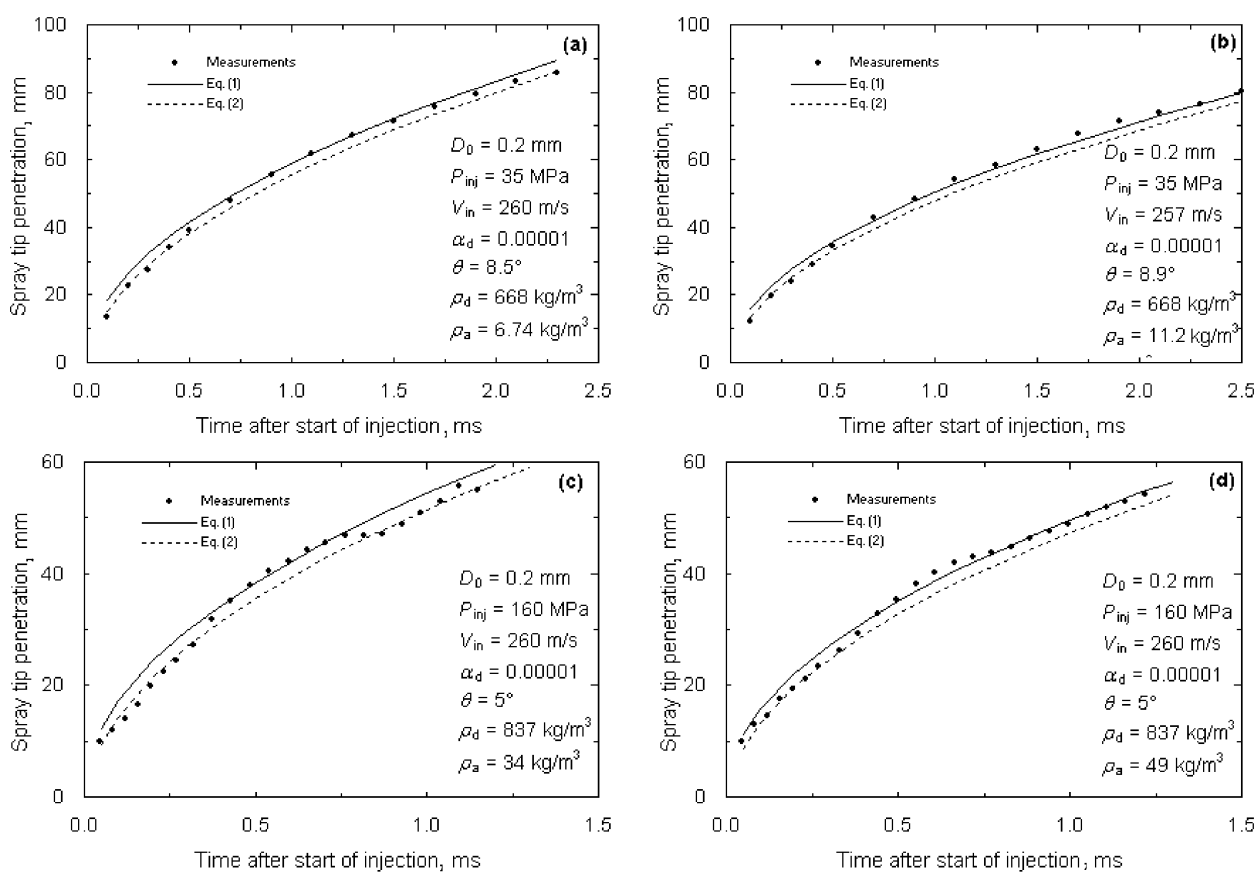

Fig. 2. Comparison between the measured spray tip penetration for the high-pressure dimethyl ether spray chamber (plots a and b) and the rapid compression diesel spray rig (plots c and d) and predictions of Eqs. (1) and (2). 
shown in Fig. 2c) Eq. (1) leads to a noticeable improvement of the prediction. In most cases, however, the errors of measurement seem to be comparable with the improved accuracy offered by Eq. (1). It should be noted that the model, suggested in $\left[{ }^{2}\right]$, is based on the assumption that the effects of turbulence on spray dynamics can be ignored. The latter effects lead to spray diffusion in directions perpendicular to the spray penetration. Taking into account this effect leads to a new spray penetration model, which predicts that $s \propto t^{3 / 2}\left[{ }^{4}\right]$. Although this dependence has been occasionally observed in our experiment, it cannot be considered as typical.

\section{ACKNOWLEDGEMENTS}

The authors would like to thank Dr. Dave Kennaird for his assistance in gathering some of the data presented. Technical and financial support from Ricardo Consulting Engineers and the EPSRC is gratefully acknowledged. Financial support from Korea Science and Engineering Foundation (grant No. 2002-1-304000120-3) is also acknowledged.

\section{REFERENCES}

1. Faeth, G. M., Hsiang, L.-P. and Wu, P.-K. Structure and breakup properties of sprays. Int. J. Multiphase Flow, 1995, 21:Suppl, 99-127.

2. Sazhin, S. S., Feng, G. and Heikal, M. R. A model for fuel spray penetration. Fuel, 2001, 80, 2171-2180.

3. Sazhin, S. S., Crua, C., Kennaird, D. and Heikal, M.R. The initial stage of fuel spray penetration. Fuel, 2003, 82, 875-885.

4. Pozorski, J., Sazhin, S. S., Wacławczyk, M., Crua, C., Kennaird, D. and Heikal, M. Spray penetration in a turbulent flow. Flow, Turbulence Combust., 2002, 68, 153-165.

5. Kennaird, D. A., Crua, C., Heikal, M., Morgan, R., Bar, F. and Sapsford, S. A new high pressure diesel spray research facility. In IMechE Conference Transactions 2000-8. International Conference on Computational and Experimental Methods in Reciprocal Engines. London, 2000, 179-188.

6. Crua, C. Combustion Processes in a Diesel Engine. PhD Thesis, University of Brighton, Brighton, 2002.

7. Crua, C., Kennaird, D. A. and Heikal, M. R. Laser induced incandescence study of diesel soot formation in a rapid compression machine at elevated pressures. Combust. Flame, 2003, 135, 475-488.

8. Hwang, J.-S., Ha, J.-S. and No, S.-Y. Spray characteristics of DME in common rail injection system. In Busan Engine International Symposium. Busan, Korea, 2001.

9. Hwang, J.-S., Ha, J.-S. and No, S.-Y. Spray characteristics of DME in conditions of common rail injection system. In The Seventh Annual Conference on Liquid Atomization and Spray Systems-Asia. Tainan, Taiwan, 2002.

10. Stumpp, G. and M. Ricco, M. Common Rail: An Attractive Fuel Injection System for Passenger Car and DI Diesel Engines. SAE Report No. 960870, 1996. 


\section{Kütuse sissepritse mudelid}

\section{Sergei Sazhin, Cyril Crua, Jin-Sik Hwang, Soo-Young No ja Morgan Heikal}

On antud lühike ülevaade Brightoni Ülikoolis (Suurbritannia) välja töötatud diiselkütuste sissepritse mudelitest. Need käsitlevad sissepritse sisemist staadiumi ja kahefaasilise voolamise staadiumi juhul, kui võib ignoreerida osakeste ja gaasi kiiruste erinevust. Sissepritse kahefaasilise mudeli tulemusi on võrreldud sissepritse eksperimentaalse uurimise tulemustega. Eksperimentide läbiviimisel on kasutatud Brightoni Ülikooli diiselkütuse kiire pihustamise aparatuuri ja Chungbuki Rahvusülikooli (Korea) dimetüüleetri kõrgsurve pihustamise kambrit. Mõlemal juhul on katsetulemused heas kooskõlas teoreetiliste mudelite poolt prognoositavatega. 